\title{
The Provision of Active After-School Clubs for Children in English Primary Schools: Implications for Increasing Children's Physical Activity
}

\author{
Ben R. Davies*, Lesley Wood, Kate Banfield, Mark J. Edwards, Russell Jago \\ Centre for Exercise, Nutrition \& Health Sciences, School for Policy Studies, University of Bristol, Bristol, UK \\ Email: ${ }^{*}$ ben.davies@bristol.ac.uk
}

Received 24 May 2014; revised 3 July 2014; accepted 22 July 2014

Copyright (C) 2014 by authors and Scientific Research Publishing Inc.

This work is licensed under the Creative Commons Attribution International License (CC BY).

http://creativecommons.org/licenses/by/4.0/

(c) (i) Open Access

\begin{abstract}
Introduction: The transition from primary to secondary school is a period when physical activity (PA) declines. Interventions delivered during curriculum time have had limited impact on PA. The after-school period may offer a valuable opportunity to increase children's PA. In order to identify how best to implement after-school PA interventions for older primary school children, more information regarding the provision of after-school clubs is required. This paper examined the current after-school club provision of English primary schools. Methods: All state-funded primary schools in England $(n=15,307)$ were sent an online questionnaire in two phases during 2013. Schools were asked about the active and non-active after-school clubs on offer to year 5 and year 6 pupils and the days on which they run, the number of children attending each after-school club, who funds the club and who leads the club. Results: Responding schools (501) were reasonably representative of the national profile. Of the 2413 clubs reported, more non-active than active clubs (5.3 vs. 4.8 per school) were described. Football was the most frequently reported activity (offered by $79.5 \%$ of schools), with netball and dance being offered by $45.3 \%$ and $44.1 \%$ of schools, respectively. A high proportion of clubs was funded by schools or parents $(88.6 \%)$ and more than 40\% were led by external parties. Conclusions: A number of PA programmes are provided after-school but current provision is dominated by team sports and thus, there is a need for non-sport specific PA clubs. Furthermore, there is a need to find cost-effective methods of delivering after-school PA programmes.
\end{abstract}

\section{Keywords}

After-School, Extracurricular, Clubs, Active, Primary School

\footnotetext{
${ }^{*}$ Corresponding author.
}

How to cite this paper: Davies, B.R., Wood, L., Banfield, K., Edwards, M.J. and Jago, R. (2014) The Provision of Active AfterSchool Clubs for Children in English Primary Schools: Implications for Increasing Children's Physical Activity. Open Journal of Preventive Medicine, 4, 598-605. http://dx.doi.org/10.4236/ojpm.2014.47069 


\section{Introduction}

Physical activity (PA) is associated with lower levels of cardio-metabolic risk factors among children and adults [1]. It is recommended that children engage in 60 minutes of moderate to vigorous PA (MVPA) each day [2]. Population-based surveys indicate that many children do not meet this recommendation [3] [4] and PA levels decline during childhood [5]. As PA behaviours [6] [7] tend to track into adulthood, it is important to establish healthy behaviours early. The end of primary school and start of secondary school has been identified as an important period when PA declines [5]. As such, strategies to increase PA and promote future PA engagement in older primary school children (years 5 and 6 ) are needed.

Increasing children's PA levels is one of the UK government's key public health policy targets [2], but encouraging children to become more active remains a major challenge. Unfortunately, the majority of child PA interventions have had limited success [8] [9]. Interventions have mainly been delivered during curriculum hours and are therefore competing with "core" academic subjects, English, mathematics and science [10] [11]. If curriculum-time PA interventions are not a feasible route for the promotion of child PA, then an alternative approach is needed [10]. The after-school period may be the only period of the day when children can decide if, and how, they are to be active, and has been identified as "critical hours" for young people's PA [12].

In the UK, curriculum time PA tends to be limited to a maximum of two hours of Physical Education (PE) per week [13]. The 2009-10 Physical Education (PE) and Sport Survey reported that 84.0\% of pupils in years 1 to 11, from English schools, participated in at least two hours of curriculum PE per week [14]. This proportion was higher (95.0\%) in children in the upper years of primary school (years 3 - 6) but started to decline rapidly once pupils moved to secondary school. The same survey found that within each year of primary education only $7 \%$ of children achieved three hours of PA through curriculum time PE alone. Therefore, the provision of after-school clubs that offer additional PA may be an important factor in increasing PA amongst school-aged children.

In order to evaluate the impact of after-school PA clubs for the promotion of PA engagement in year 5 (Y5) and year 6 (Y6) children, it is important to identify how an after-school PA programme could be implemented based on current provision. There is a lack of information about the provision of after-school clubs for primary school aged children. The aim of this paper was to identify the current after-school club provision for children in years 5 and 6 from primary schools in England, with a focus on clubs offering physical activities or "active clubs".

\section{Method}

Ethical approval for the survey was granted by the School for Policy Studies Research Ethics Committee at the University of Bristol as part of an ongoing study, the Action 3:30 Project (ref: Action 3:30 Project) [15]. An online questionnaire was sent to all state-funded primary schools in England $(n=15,307)$, in two phases: phase 1 to the first 7563 in June 2013, and phase 2 to the remaining 7744 schools in October 2013. The questionnaire was sent out four times at each phase. This included the initial invite to participate and three reminders, with one week between each repeated dispatch. Participants were notified that by completing and submitting the online questionnaire, they were consenting to participate in the survey. All responding schools were entered into a raffle draw with the chance to receive one of two $£ 50$ gift vouchers. The questionnaire was designed with the aim of collecting current information about after-school club provision in state-funded English primary schools. The questionnaire specifically asked about: the number of boys and girls in Y5 and Y6; the active and non-active after-school clubs on offer to Y5 and Y6 children and the days on which they run; the number of children attending each after-school club; who funds the club and who leads the club. Each responding school was also asked to provide its Unique Reference Number (URN).

The number of active and non-active clubs per school was derived by generating two new variables containing the sum of non-active clubs and active clubs reported by each school. Two variables (for example, Football team; Football nonteam) were then generated for each active club type and each variable was coded 0 (not applicable) or 1 (applicable) as appropriate. Two new variables were created, indicating the number of team clubs and non-team clubs offered by each school, by summing the two sets of variables across each row. The number of pupils participating in each of these two types of club was then computed for each school. Similar methods were used to derive the number of clubs within each school that were available to Y5 and Y6 pupils, from which it was possible to generate a third variable if the club was available to both year groups. This process was re- 
peated for each listed club to enable information about days of the week, funding, and leadership to be reported. Finally, the dataset was merged into the January 2013 school census [16], using the school URN as the linking variable, and the responding schools were compared with all state-funded English primary schools in terms of size, funding and markers of social deprivation. All data management and analyses were performed in Stata version 12.0 (College Station, TX).

\section{Results}

Responses were received from 501 schools, 248 (49.5\%) at phase 1 and 253 (50.5\%) at phase 2). Overall, the sample was reasonably similar to the national profile, although responding schools were somewhat less deprived, based on eligibility for free school meals (FSM), and were smaller than the national average (222.9 vs. 248.8 pupils) (Table 1).

A total of 2413 clubs was reported and, on average, schools reported offering more non-active clubs than active clubs (5.3 vs. 4.8 per school) (Table 2). Of the 501 schools, 13 schools reported offering only non-active clubs and all subsequent results are therefore based on responses from the 488 schools that reported offering at least one active club. Schools reported offering the same average number of team and non-team sports (2.4 per school). The majority of schools (445; 91.0\%) offered at least one after school activity club to both Y5 and Y6 pupils and all clubs were somewhat more likely to be run midweek rather than on Mondays and Fridays.

Football was the most widely offered extra-curricular activity (388 schools; 79.5\%), with netball and dance each being provided by over 200 schools (Table 3). Taking the average number of participants into account, up

Table 1. Comparison of responding schools with characteristics of all English primary schools (492 of 501 responding schools).

\begin{tabular}{|c|c|c|c|c|}
\hline & \multicolumn{2}{|c|}{ Sample $(\mathrm{n}=492)$} & \multicolumn{2}{|c|}{ Population $(\mathrm{n}=16,784)$} \\
\hline & Mean & SD & Mean & SD \\
\hline \multirow[t]{3}{*}{ Roll number (FTE) } & 222.9 & 142.6 & 248.8 & 138.1 \\
\hline & \multicolumn{4}{|c|}{ Categorical variables } \\
\hline & $\mathrm{n}$ & $\%$ & $\mathrm{n}$ & $\%$ \\
\hline \multicolumn{5}{|l|}{ Deprivation } \\
\hline Eligibility for FSM (of N used for FSM calculations) & N/A & 16.4 & N/A & 18.4 \\
\hline Take up of FSM (of N used for FSM calculations) & N/A & 14.3 & N/A & 15.7 \\
\hline Take up of FSM (of eligible) & N/A & 86.1 & N/A & 84.9 \\
\hline \multicolumn{5}{|l|}{ Ethnicity } \\
\hline ESL & N/A & 15.9 & N/A & 16.3 \\
\hline White British ethnic origin & N/A & 60.9 & N/A & 57.5 \\
\hline \multicolumn{5}{|l|}{ Funding source: } \\
\hline Academy Converters & 31 & 6.3 & 742 & 4.6 \\
\hline Academy Sponsor Led & 0 & 0 & 197 & 1.2 \\
\hline Community School & 246 & 50.0 & 9272 & 55.2 \\
\hline Foundation School & 13 & 2.6 & 550 & 3.3 \\
\hline Free Schools & 2 & 0.4 & 37 & 0.2 \\
\hline Voluntary Aided School & 107 & 21.8 & 3547 & 21.1 \\
\hline Voluntary Controlled School & 93 & 18.9 & 2409 & 14.4 \\
\hline
\end{tabular}

a. 1 responding school was a Middle-deemed-primary school; 492 of 501 responding schools could be merged to the national dataset based on URN; the remaining schools did not provided a school name or URN so could not be identified; N/A-The total number of pupils in all schools is uninformative. 
Table 2. Mean number of clubs per school $(n=501)$; days clubs were run; and availability to Y5 and Y6 pupils.

\begin{tabular}{|c|c|c|c|c|c|c|c|c|c|c|}
\hline & Mean & \multicolumn{2}{|c|}{ SD } & \multicolumn{2}{|r|}{ Median } & \multicolumn{2}{|r|}{ IQR } & \multicolumn{3}{|c|}{ Range } \\
\hline Non-active clubs & 5.3 & \multicolumn{2}{|c|}{3.1} & \multicolumn{2}{|r|}{5.0} & \multicolumn{3}{|c|}{3 to 7} & \multicolumn{2}{|c|}{1 to 19} \\
\hline Active clubs: & 4.8 & \multicolumn{2}{|c|}{3.1} & \multicolumn{2}{|r|}{4.0} & \multicolumn{3}{|c|}{3 to 6} & \multicolumn{2}{|c|}{0 to 18} \\
\hline Team clubs & 2.4 & \multicolumn{2}{|c|}{1.6} & \multicolumn{2}{|r|}{2.0} & \multicolumn{3}{|c|}{1 to 3} & \multicolumn{2}{|c|}{0 to 8} \\
\hline \multirow[t]{2}{*}{ Non-team clubs } & 2.4 & \multicolumn{2}{|c|}{1.9} & \multicolumn{2}{|r|}{2.0} & \multicolumn{3}{|c|}{1 to 4} & \multicolumn{2}{|c|}{0 to 12} \\
\hline & \multicolumn{2}{|c|}{ Monday } & \multicolumn{2}{|c|}{ Tuesday } & \multicolumn{2}{|c|}{ Wednesday } & \multicolumn{2}{|c|}{ Thursday } & \multicolumn{2}{|c|}{ Friday } \\
\hline \multirow{4}{*}{ N (\%) schools offering clubs on each day } & $\mathrm{n}$ & $\%$ & $\mathrm{n}$ & $\%$ & $\mathrm{n}$ & $\%$ & $\mathrm{n}$ & $\%$ & $\mathrm{n}$ & $\%$ \\
\hline & 294 & 60.3 & 332 & 68.1 & 335 & 68.7 & 336 & 68.9 & 257 & 52.7 \\
\hline & \multicolumn{3}{|c|}{ Available to Y5 } & \multicolumn{2}{|c|}{ Available to Y6 } & \multicolumn{5}{|c|}{ Available to Y5 and Y6 } \\
\hline & $\mathrm{n}$ & & $\%$ & $\mathrm{n}$ & $\%$ & & $\mathrm{n}$ & & $\%$ & \\
\hline $\begin{array}{c}\text { N (\%) schools offering clubs to Y5 and } \\
\text { Y6 }\end{array}$ & 452 & & 92.6 & 447 & 91.6 & & 445 & & 91 & \\
\hline
\end{tabular}

Table 3. Mean number of pupils per activity.

\begin{tabular}{|c|c|c|c|c|c|c|}
\hline Activity & & N schools & $\begin{array}{l}\text { \% of schools } \\
\text { offering }\end{array}$ & $\begin{array}{c}\mathrm{N} \text { ppts } \\
\text { per club }\end{array}$ & $\begin{array}{c}\mathrm{N} \text { ppts } \\
\text { team sports }\end{array}$ & $\begin{array}{c}\mathrm{N} \text { ppts } \\
\text { non-team sports }\end{array}$ \\
\hline Athletics & Non-Team & 183 & 37.5 & 22.5 & & 22.5 \\
\hline Badminton & Non-Team & 32 & 6.6 & 13.8 & & 13.8 \\
\hline Baseball & Team & 2 & 0.4 & 15.0 & 15.0 & \\
\hline Basketball & Team & 75 & 15.4 & 17.9 & 17.9 & \\
\hline Boccia & Team & 3 & 0.6 & 15.7 & 15.7 & \\
\hline Bowling & Non-Team & 1 & 0.2 & 15.0 & & 15.0 \\
\hline Bowls & Non-Team & 2 & 0.4 & 14.5 & & 14.5 \\
\hline Boxing & Non-Team & 7 & 1.4 & 15.5 & & 15.5 \\
\hline Canoeing & Non-Team & 3 & 0.6 & 14.0 & & 14.0 \\
\hline Cheerleading & Team & 32 & 6.6 & 18.2 & 18.2 & \\
\hline Circus skills & Non-Team & 6 & 1.2 & 28.6 & & 28.6 \\
\hline Climbing & Non-Team & 3 & 0.6 & 9.0 & & 9.0 \\
\hline Cricket & Team & 138 & 28.3 & 18.1 & 18.1 & \\
\hline Cycling & Non-Team & 25 & 5.1 & 24.0 & & 24.0 \\
\hline Dance & Non-Team & 215 & 44.1 & 19.2 & & 19.2 \\
\hline Dodgeball & Team & 42 & 8.6 & 19.7 & 19.7 & \\
\hline Fencing & Non-Team & 26 & 5.3 & 17.0 & & 17.0 \\
\hline Fitness & Non-Team & 44 & 9.0 & 20.5 & & 20.5 \\
\hline Football & Team & 388 & 79.5 & 22.2 & 22.2 & \\
\hline Frisbee & Team & 3 & 0.6 & 15.0 & 15.0 & \\
\hline Goalball & Non-Team & 0 & 0.0 & - & & 0.0 \\
\hline Golf & Non-Team & 23 & 4.7 & 14.8 & & 14.8 \\
\hline
\end{tabular}




\section{Continued}

\begin{tabular}{|c|c|c|c|c|c|c|}
\hline Gymnastics & Non-Team & 123 & 25.2 & 17.7 & & 17.7 \\
\hline Handball & Team & 10 & 2.0 & 14.6 & 14.6 & \\
\hline Hockey & Team & 54 & 11.1 & 18.9 & 18.9 & \\
\hline Judo & Non-Team & 34 & 7.0 & 16.8 & & 16.8 \\
\hline Kabaddi & Non-Team & 0 & 0.0 & - & & 0.0 \\
\hline Karate & Non-Team & 37 & 7.6 & 17.2 & & 17.2 \\
\hline Kite flying & Non-Team & 1 & 0.2 & & & 0.0 \\
\hline Lacrosse & Team & 4 & 0.8 & 19.4 & 19.4 & \\
\hline Martial arts & Non-Team & 35 & 7.2 & 18.9 & & 18.9 \\
\hline Mountaineering & Non-Team & 0 & 0.0 & - & & 0.0 \\
\hline Multi-skills & Non-Team & 166 & 34.0 & 17.3 & & 17.3 \\
\hline Netball & Team & 221 & 45.3 & 18.1 & 18.1 & \\
\hline Orienteering & Non-Team & 10 & 2.0 & 16.5 & & 16.5 \\
\hline Outdoor and adventurous activity & Non-Team & 21 & 4.3 & 23.5 & & 23.5 \\
\hline Rounders & Team & 84 & 17.2 & 19.4 & 19.4 & \\
\hline Rowing & Team & 5 & 1.0 & 13.0 & 13.0 & \\
\hline Rugby & Team & 117 & 24.0 & 18.2 & 18.2 & \\
\hline Sailing & Non-Team & 5 & 1.0 & 9.4 & & 9.4 \\
\hline Skating & Non-Team & 1 & 0.2 & 30.0 & & 30.0 \\
\hline Skiing & Non-Team & 2 & 0.4 & 12.0 & & 12.0 \\
\hline Softball & Team & 1 & 0.2 & & 0.0 & \\
\hline Squash & Team & 1 & 0.2 & 24.0 & 24.0 & \\
\hline Swimming & Non-Team & 40 & 8.2 & 28.3 & & 28.3 \\
\hline Table Tennis & Non-Team & 25 & 5.1 & 14.3 & & 14.3 \\
\hline Tennis & Non-Team & 60 & 12.3 & 14.3 & & 14.3 \\
\hline Trampolining & Non-Team & 1 & 0.2 & & & 0.0 \\
\hline Triathlon & Non-Team & 1 & 0.2 & & & 0.0 \\
\hline Volleyball & Team & 3 & 0.6 & 21.0 & 21.0 & \\
\hline Waterpolo & Team & 2 & 0.4 & & 0.0 & \\
\hline Yoga & Non-Team & 23 & 4.7 & 11.1 & & 11.1 \\
\hline Skipping & Non-Team & 2 & 0.4 & 21.0 & & 21.0 \\
\hline Girls' football & Team & 3 & 0.6 & 16.0 & 16.0 & \\
\hline Multi-sports & Non-Team & 19 & 3.9 & 18.7 & & 18.7 \\
\hline Gardening & Non-Team & 14 & 2.9 & 13.5 & & 13.5 \\
\hline Archery & Non-Team & 6 & 1.2 & 15.8 & & 15.8 \\
\hline Other non-team activities & Non-Team & 28 & 5.7 & 16.6 & & 16.6 \\
\hline
\end{tabular}




\begin{tabular}{lccccc} 
Continued & \multicolumn{1}{l}{} & & & \\
\hline Other team activities & Team & 1 & 0.2 & 20.0 & 20.0 \\
\hline Total N clubs & 2413 & & & \\
\hline Mean N overall & & 17.8 & 18.1 & 17.5 \\
Stddev & & 4.4 & 2.8 & 5.2 \\
\hline
\end{tabular}

a. N school 488.

Table 4. Length of time clubs ran for; funding of clubs; leadership of clubs.

\begin{tabular}{|c|c|c|c|c|}
\hline Length & $\begin{array}{l}\text { N schools with clubs lasting } \\
<30 \text { mins }\end{array}$ & \multicolumn{2}{|c|}{$\begin{array}{l}\text { N schools with clubs lasting } \\
30 \text { to } 45 \text { mins }\end{array}$} & $\begin{array}{l}\text { N schools with clubs lasting } \\
>45 \text { mins }\end{array}$ \\
\hline$n$ clubs $(\mathrm{N}=2289)$ & 67 & \multicolumn{2}{|c|}{561} & 1661 \\
\hline$\%$ age of all clubs & 2.9 & \multicolumn{2}{|c|}{24.5} & 72.6 \\
\hline Funding & School & Parents & $\begin{array}{c}\text { External } \\
\text { organisation }\end{array}$ & No perceived cost \\
\hline$n$ clubs $(\mathrm{N}=2231)$ & 1244 & 731 & 213 & 43 \\
\hline$\%$ age of all clubs & 55.8 & 32.8 & 9.5 & 1.9 \\
\hline Leadership & School employee & $\begin{array}{l}\text { Local sport } \\
\text { partnership }\end{array}$ & Sporting NGB & Other \\
\hline n clubs $(\mathrm{N}=1883)$ & 1110 & 231 & 138 & 404 \\
\hline$\%$ age of all clubs & 58.9 & 12.3 & 7.3 & 21.5 \\
\hline
\end{tabular}

to 46,000 pupils participated in the clubs reported in the survey, of which 8617 played football and 4128 took part in dance. Assuming that the responding sample was reasonably representative of all schools, football as an after-school activity might engage almost 289,000 children each week. The average attendance at clubs was 17.8 (4.4) children and this was similar for both team and non-team sports. Almost three-quarters $(1661 ; 73 \%)$ of clubs ran for at least 45 minutes, with 67 (3\%) clubs lasting for under 30 minutes (Table 4).

The majority of clubs (88.6\%) were funded either by the school or parents (Table 4), whilst over half (58.9\%) were said to be led by a school employee. Of the remaining, $20 \%$ were led either by a Local Sport Partnership (12\%) or by a Sporting National Governing Body (7\%). The remaining 22\% were led by some other person or organisation, such as a self-employed dance-teacher paid directly by parents.

\section{Discussion}

Many children are not meeting the recommended levels of MVPA. In order to identify how an after-school PA programme could be implemented to increase children's PA, this paper explored the current after-school club provision of English primary schools. On average, schools offered fewer "active" compared with "non-active" clubs ( 4.8 vs 5.3 clubs per school, respectively). Additionally, data shows that fewer schools run clubs on Mondays and Fridays compared with days in the middle of the week. This may suggest that there could be scope to increase the provision of active after-school clubs, particularly at the beginning and end of the week.

The school demographic data from this survey shows that, despite a response rate of only 3.3\%, the responding schools were reasonably representative of the national profile of English primary schools. Only eight activities were offered by more than $20 \%$ of the schools surveyed, half of which were team sports. The majority of activities were team sports, with only one (multi-skills) focusing on non-competitive movement skill development. Previous research [17] suggests that children may be more encouraged to participate in PA when provided with a variety of activities as opposed to just competitive sports. Thus, the high proportion of sport specific and team games on offer after-school may discourage some children from participating in PA. Overall there appears to be a lack of provision of active after-school clubs that might appeal to children who lack fundamental movement skills.

Cost is likely to affect the provision of after school clubs. The current survey found that a high proportion of after-school clubs were funded by either the school (55.8\%) or parents (32.8\%), with only $11 \%$ of the clubs be- 
ing funded externally, or having no perceived cost. Additionally, $41 \%$ of the clubs offered were led by a non-school employee. Although it is difficult to estimate costs to the schools or parents, due to the large variability in costs of after-school clubs delivered externally, the clubs delivered by external bodies are likely to incur a greater financial cost to the school or parents compared with using school staff. The range of funding sources used by schools makes it difficult to evaluate the time-cost of current provision and scope to use after-school clubs as a cost-effective approach for promoting PA.

The data presented in this paper suggests that there might be scope within English primary schools for new programmes that focus on promoting physical activity through non-sport specific after-school activities. These programmes could be delivered by training existing school staff and as such may provide a cost-effective means of increasing physical activity. Future work should explore the feasibility of implementing such an intervention in English primary schools.

\section{Strengths and Limitations}

The low response rate of this school survey is a limitation. The sample does, however, appear to be reasonably similar to the national profile and may be representative of the general population. A further limitation of this work is the different times of year that the two phases of the survey were sent out (June and October). It is possible that responses reflected the seasonal nature of the clubs being offered contemporarily (e.g. cricket during the summer term and rugby during the autumn terms), rather than more general provision throughout the year. However, given that the response rates from both phases were similar, any seasonal bias is likely to have balanced out between the two assessment periods. Additionally, schools were not asked to provide information on the costs of specific after-school clubs or the overall cost of clubs to schools. It would be of value to account for cost information when designing an after-school PA intervention programme. The questionnaire also failed to ascertain any information regarding the level of physical activity engagement at the clubs. Therefore, further research is needed which investigates the cost to schools or parents of delivering individual after-school clubs and which assesses what those clubs entail.

\section{Conclusion}

The results of this survey demonstrate the requirement for greater provision of active after-school clubs. Based on current provision, there is a need for more clubs that focus on the development of fundamental movement skills rather than individual team sports. Additionally, the large proportion of after-school clubs funded by schools and parents and run by external bodies highlights the potential benefit of schools using their own appropriately trained staff to deliver physically active after school clubs.

\section{Acknowledgements}

This study was funded by the National Prevention Research Initiative which is supported by Alzheimer's Research Trust; Alzheimer's Society; Biotechnology and Biological Sciences Research Council; British Heart Foundation; Cancer Research UK; Chief Scientist Office, Scottish Government Health Directorate; Department of Health; Diabetes UK; Economic and Social Research Council; Health and Social Care Research and Development Division of the Public Health Agency (HSC R\&D Division); Medical Research Council; The Stroke Association; Wellcome Trust; Welsh Assembly Government; and World Cancer Research Fund (MRC reference-MR/J000191/1).

\section{Data Sharing}

Data from the Action 3:30 Project will be made available to external collaborators from September 2015. From this point, we would be happy for external collaborators to access these data according to data transfer agreements that will have been developed by then. Information regarding this access will be made available on the study website (http://www.bristol.ac.uk/sps/researchprojectpages/action330/).

\section{References}

[1] Strong, W.B., et al. (2005) Evidence Based Physical Activity for School-Age Youth. The Journal of Pediatrics, 146, 732-737. http://dx.doi.org/10.1016/j.jpeds.2005.01.055 
[2] Department of Health (2011) Start Active, Stay Active: A Report on Physical Activity for Health from the Four Home Countries’ Chief Medical Officers. In: Protection, D.O.H.P.H.I.A., Ed., London.

[3] Troiano, R.P., et al. (2008) Physical Activity in the United States Measured by Accelerometer. Medicine and Science in Sports and Exercise, 40, 181-188. http://dx.doi.org/10.1249/mss.0b013e31815a51b3

[4] Craig, R., Mindell, J. and Hirani, V. (2009) Health Survey for England 2008. Volume 1: Physical Activity and Fitness. Health Survey for England, 8-395.

[5] Nader, P.R., Bradley, R.H., Houts, R.M., Mcritchie, S.L. and O’brien, M. (2008) Moderate-to-Vigorous Physical Activity from Ages 9 to 15 Years. JAMA: The Journal of the American Medical Association, 300, 295-305. http://dx.doi.org/10.1001/jama.300.3.295

[6] Malina, R.M. (1996) Tracking of Physical Activity and Physical Fitness across the Lifespan. Research Quarterly for Exercise and Sport, 67, S48-S57. http://dx.doi.org/10.1080/02701367.1996.10608853

[7] Twisk, J.W.R., Kemper, H.C.G. and Van Mechelen, W. (2000) Tracking of Activity and Fitness and the Relationship with Cardiovascular Disease Risk Factors. Medicine and Science in Sports and Exercise, 32, 1455-1461. http://dx.doi.org/10.1097/00005768-200008000-00014

[8] Sluijs, E.M.F.V., Mcminn, A.M. and Griffin, S.J. (2007) Effectiveness of Interventions to Promote Physical Activity in Children and Adolescents: Systematic Review of Controlled Trials. BMJ, 335, 703. http://dx.doi.org/10.1136/bmj.39320.843947.BE

[9] Dobbins, M., De Corby, K., Robeson, P., Husson, H. and Tirilis, D. (2009) School-Based Physical Activity Programs for Promoting Physical Activity and Fitness in Children and Adolescents Aged 6 - 18. Cochrane Database of Systematic Reviews, 1, Article ID: CD007651.

[10] Jago, R. and Baranowski, T. (2004) Non-Curricular Approaches for Increasing Physical Activity in Youth: A Review. Preventive Medicine, 39, 157-163. http://dx.doi.org/10.1016/j.ypmed.2004.01.014

[11] Pate, R.R. and O’neill, J.R. (2009) After-School Interventions to Increase Physical Activity among Youth. British Journal of Sports Medicine, 43, 14-18. http://dx.doi.org/10.1136/bjsm.2008.055517

[12] Atkin, A.J., Gorely, T., Biddle, S.J., Cavill, N. and Foster, C. (2011) Interventions to Promote Physical Activity in Young People Conducted in the Hours Immediately after School: A Systematic Review. International Journal of Behavioral Medicine, 18, 176-187. http://dx.doi.org/10.1007/s12529-010-9111-z

[13] Speednet (1999) Primary School Physical Education-Speednet Survey Makes Depressing Reading. British Journal of Physical Education, 30, 19-20.

[14] Quick, S., Simon, A. and Thornton, A. (2010) PE and Sport Survey 2009/10. https://www.gov.uk/government/publications/pe-and-sport-survey-2009-to-2010

[15] Jago, R., et al. (2013) Action 3:30: Protocol for a Randomized Feasibility Trial of a Teaching Assistant Led Extracurricular Physical Activity Intervention. Trials, 14, 122. http://dx.doi.org/10.1186/1745-6215-14-122

[16] Department for Education (2013) Schools, Pupils, and Their Characteristics. https://www.gov.uk/government/publications/schools-pupils-and-their-characteristics-january-2013

[17] Allender, S., Cowburn, G. and Foster, C. (2006) Understanding Participation in Sport and Physical Activity among Children and Adults: A Review of Qualitative Studies. Health Education Research, 21, 826-835.

http://dx.doi.org/10.1093/her/cyl063 
Scientific Research Publishing (SCIRP) is one of the largest Open Access journal publishers. It is currently publishing more than 200 open access, online, peer-reviewed journals covering a wide range of academic disciplines. SCIRP serves the worldwide academic communities and contributes to the progress and application of science with its publication.

Other selected journals from SCIRP are listed as below. Submit your manuscript to us via either submit@scirp.org or Online Submission Portal.
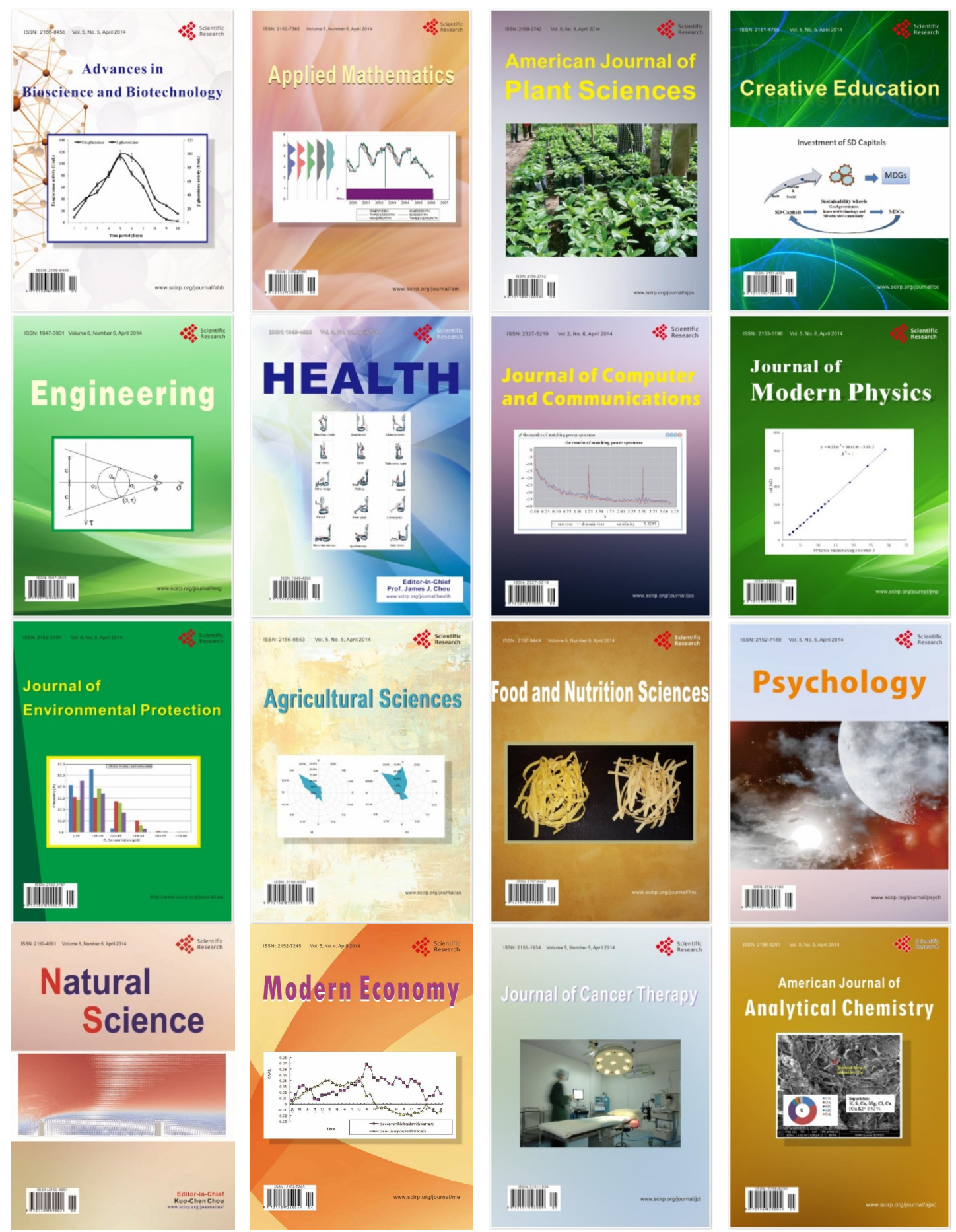